\title{
Association between Grain Yield, Grain Quality and Morpho-physiological Traits along Ten Cycles of Recurrent Selection in Bread Wheat (Triticum aestivum L.)
}

\author{
R.H. Maich ${ }^{1 *}$, M.E. StefFolani ${ }^{1,2}$, J.A. Di RIENZO ${ }^{1}$ and A.E. LeÓN ${ }^{1,2}$ \\ ${ }^{1}$ Facultad de Ciencias Agropecuarias, Universidad Nacional de Córdoba (UNC), Córdoba, Argentina \\ ${ }^{2}$ Instituto de Ciencia y Tecnología de Alimentos Córdoba (ICyTAC) (CONICET-UNC), Córdoba, Argentina
}

(Received 11 March 2016; Accepted 12 April 2016;

Communicated by A. Aniol)

\begin{abstract}
The objective of the present investigation was to examine the relationships between agronomical behavior and grain quality along ten cycles of a recurrent selection program performed under rainfed condition. Twenty-four lines, four for each one of the $0,2,4,6,8$ and 10 cycles of recurrent selection, were evaluated for two consecutive years (2011 and 2012). The experimental lines were evaluated under conventional (CT) and no tillage (NT) systems. Grain yield and grain weight were determined and harvest index and grain number estimated. Flour protein content, sodium dodecyl sulphate sedimentation (IS-SDS) and lactic acid SRC (LASRC) were considered as end-use quality predictive tests. The Spearman correlation coefficient was used to measure the relationships among yield, its components and grain quality parameters. Within the context of CT, flour protein content was negatively associated with all the agronomic variables. The IS-SDS has a negative association with the grain weight; meanwhile, LASRC associated positively with all the agronomic variables. When wheat was grown in NT, the relationship between IS-SDS and harvest index, like LASRC with all agronomic traits, was positive. Confining the discussion to the $\mathrm{CT}$ results, after ten cycles of recurrent selection the highest grain yield achieved was accompanied by a decrease in protein percentage. However, the decrease in the percentage of protein in more advanced selection cycles was offset by an improvement of its quality.
\end{abstract}

Keywords: yield, grain protein, wheat breeding

\section{Introduction}

In a context where agricultural practices are likely to go toward extensive systems with no tillage, it is important to determine the genetic improvement of winter wheat (Triticum aestivum L.) not only in conventional (CT) but also in no tillage (NT) systems. Grain yield (GY) and protein content (PROT), through its contribution to end-use quality, are the most important traits determining the economic value of bread wheat crop (Delzer et al. 1995). The development of high grain yield varieties both resistant to biotic and abiotic stressing factors, and with good breadmaking quality, are the main achievements for bread wheat breeding programs (Tayyar 2010). Moreover, comparisons of cultivars can

*Corresponding author; E-mail: rimaich@aro.unc.edu.ar 
throw an interesting light on the evolutionary trend in morpho-physiological, agronomical and qualitative characteristics (De Vita et al. 2007). Various approaches have been used. For example, progress has been evaluated from the differences between historic check cultivars and the mean yield of highest yielding lines, cultivars from different eras in common environments (Giunta et al. 2007), or materials derived from successive cycles of recurrent selection (RS) (Maich and Di Rienzo 2014).

Genetic improvements have made substantial contributions to wheat yield increases in many countries. Most of these studies showed that GY increase is mainly associated with increased harvest index (HI), small or negligible increases in total biomass production, reduced plant height, and increased grain number per square meter (GN) (De Vita et al. 2007; Zhou et al. 2007), without altering grain weight (GW) (Brancourt-Hulmel et al. 2003).

As in other crops, the increase of carbon availability for grains is accompanied by a negative relationship between GY and PROT (Oury and Godin 2007). This protein drop appears not to be linked to direct genetic effects but to a dilution effect due to an increase in the amount of carbohydrates (De Vita et al. 2007). However, decreases in protein and wet gluten contents were compensated for by an improvement in protein quality (Hristov et al. 2010). Sometimes grain protein content was not reflected in the quality of the flour, while the sodium dodecyl sulphate sedimentation test (IS-SDS) did (Peighambardoust et al. 2011). A negative association between IS-SDS and GY, reported by Oelofse et al. (2010), is attributed to the highly positive correlation between IS-SDS and PROT. The Lactic Acid SRC (LASRC) test is associated with glutenin network formation and gluten strength of flour. It is a good predictor for the bread making performance of wheat flours (Colombo et al. 2008).

Given the foregoing reasons, a significant genetic progress for grain yield does not necessarily bring about a decline in industrial flour quality. The objective of the present investigation was to examine the relationships between agronomical behavior and grain quality along ten cycles of a recurrent selection program performed under rainfed conditions.

\section{Material and Methods}

\section{Plant material}

Sixteen commercial varieties of bread wheat (Triticum aestivum L.) were crossed (1985) to obtain eighty-three F1 hybrid combinations used as initial population ( $\mathrm{C} 0)$ and starting point for a RS scheme with two years per cycle (evaluation and recombination). This work was carried out at the Campo Escuela de la Facultad de Ciencias Agropecuarias (Universidad Nacional de Córdoba), Cordoba (31 ${ }^{\circ} 29^{\prime} \mathrm{S} ; 64^{\circ} 00^{\prime} \mathrm{W}$ ) in central semiarid region of Argentina. On all occasions the materials were grown under rainfed conditions. S0 progenies (full sib families) were used as selection units. The selection criteria was an index combining spike related traits, grain yield and its principal physiological (biomass and harvest index) and numerical (grain weight and number) components. The plant breeding program was conducted under conventional tillage without fertilization. Seed 
bulks of the selected progenies were created for $\mathrm{C} 0, \mathrm{C} 2, \mathrm{C} 4, \mathrm{C} 6, \mathrm{C} 8$ and $\mathrm{C} 10$ populations and multiplied annually. Plants from these seed mixtures were grown at regular spaces during 2009. Four plants per cycle with satisfactory grain production for further plot evaluation were retained.

\section{Field trials}

The twenty-four lines, four for each one of the $0,2,4,6,8$ and 10 cycles of recurrent selection, were evaluated for two consecutive years (2011 and 2012) under rainfed conditions in the same site of the selection program. Experimental lines were evaluated under CT and NT systems. Because of randomization restrictions imposed by tillage practices, two replicates in complete blocks were placed in neighboring fields having several years of CT and NT practices of soil management. Experimental units were one row plots $5 \mathrm{~m}$ long, spaced $0.20 \mathrm{~m}$ apart, with a seeding rate of 250 viable seeds per square meter. At plot level, GY per square meter in $\mathrm{g}\left(\mathrm{g} \mathrm{m}^{-2}\right)$ and $\mathrm{GW}$ in $\mathrm{g}$ were determined. HI (\%) was estimated as grain to biomass yield ratio, the GN per square meter was estimated through grain yield to 1000-grain weight ratio.

\section{Quality testing}

Flour samples were obtained with an Agromatic AG AQC 109 mill (Laupen, Switzerland). The PROT was obtained using a micro Kjeldahl Approved Method 46-13 modified with boric acid (AACC 2000), the crude protein was calculated as $\mathrm{N} \times 5$.7. Protein values were adjusted to 14\% moisture. Moisture was determined using Approved Method 44-19 (AACC 2000). SDS sedimentation index values were determined using $1 \mathrm{~g}$ of flour moistened in a $25-\mathrm{mL}$ cylinder with $8 \mathrm{~mL}$ of $10 \mathrm{mg} / \mathrm{L}$ Coomassie Blue solution. The sample was allowed to stand for $3 \mathrm{~min}$ and $40 \mathrm{~s}$, vortexed for $5 \mathrm{~s}$, allowed to stand for $1 \mathrm{~min}$ and $55 \mathrm{~s}$, and then vortexed again. An SDS-lactic acid reagent $(12 \mathrm{~mL})$ was added immediately afterwards and agitated for $1 \mathrm{~min}$ in a horizontal agitator. The SDS-lactic acid reagent was prepared by mixing $20 \mathrm{~mL}$ of lactic acid solution $(10 \% \mathrm{v} / \mathrm{v})$ with $970 \mathrm{~mL}$ of SDS solution $(2 \% \mathrm{w} / \mathrm{v})$. The resulting suspension was left to stand for $14 \mathrm{~min}$ and the volume of moistened flour was measured. The test was performed by duplicates and results were expressed in $\mathrm{cm}^{3}$ (AACC 2000). The LASRC was obtained according to the Approved Method 56-11 (AACC 2000). White flour samples (5 g) were suspended with 5\% lactic acid. The samples were hydrated for $20 \mathrm{~min}$ and centrifuged at $1.000 \times \mathrm{g}$ for $15 \mathrm{~min}$. Each precipitate obtained was weighed and the LASRC for each sample was calculated according to Approved Methods (AACC 2000).

\section{Statistical analysis}

The Spearman correlation coefficient was used to measure the relationships among yield, its components and grain quality parameters. Statistical calculations were performed by InfoStat statistical software (Di Rienzo et al. 2013). 




Cereal Research Communications 45, 2017 


\section{Results}

Tables 1 and 2 summarize the relationships between variables analyzed through the Spearman correlation coefficients in CT and NT soil management, respectively.

Within the context of CT, the four agronomic traits (GY, HI, GW and GN) were positively associated with each other, except for GW and GN (Table 1). Regarding qualitative variables (PROT, IS-SDS and LASRC), PROT was positively associated with IS-SDS, as did the latter variable with LASRC (Table 1). Considering the associations between agronomic and qualitative variables, PROT was negatively associated with all the agronomic variables (Table 1). Regarding the association between predictive tests of industrial quality (IS-SDS and LASRC) and agronomic variables, the IS-SDS has a negative association with the GW variable. Meanwhile, LASRC associated positively with all the agronomic variables (Table 1).

The correlation coefficients between agronomic and quality traits, when wheat was grown in NT, are presented in Table 2. As cultivation conducted in CT, GY, HI, GN and GW variables were associated with each other positively, except for GW and GN. For qualitative variables the relationship between PROT and LASRC and between PROT and GW were negative. The relationship between IS-SDS and HI, like LASRC with all agronomic traits, was positive (Table 2).

\section{Discussion}

These results must be contextualized in the recurrent selection scheme form which the material analyzed derives from. Maich and Di Rienzo (2014) show a significant genetic progress for GY when the wheat crop was cultivated in CT, which did not occur when grown in NT. However, a significant advance was observed for grain yield per spike, a grain yield per unit area component, when the genetic gain was measured in NT. Confining our discussion to $\mathrm{CT}$ results, after ten cycles of recurrent selection the highest grain yield achieved was accompanied by a decrease in the protein percentage. The long-recognized negative relation between yield and protein content was fully substantiated. The predictive tests of flour industrial quality (IS-SDS and LASRC) show a different behavior as selection cycles occur. As it might be expected, the IS-SDS tended to be associated with agronomic variables just as they did with PROT, reaching a negative correlation only with GW. The absence of significant correlation between grain yield and IS-SDS contradicts the results obtained by other authors (Oelofse et al. 2010), where both variables were negatively associated. The relationship between LASRC and agronomic variables was opposed to what was revealed by PROT. The positive association of LASRC with all the agronomic variables questions the view that the amount (PROT) and quality (LAS$\mathrm{RC}$ ) of the proteins do not necessarily go hand in hand. The genetic progress for grain yield per spike observed in NT further supports the trend in improving the quality of flour. The decrease in the percentage of protein in the more advanced selection cycles was offset by an improvement of its quality. 
This dichotomy between quantity and quality of protein in terms of association with genetic progress for grain yield can be explained by the fact that the breeding program is conducted in a semiarid environment under rainfed conditions. Li et al. (2013) observed that the IS-SDS significantly increased when passing from no stress to drought or heat stress conditions. Comparing both soil managements, the non-tillage practice caused a significant yield reduction. In other words, under the tillage practice mentioned the crop was subjected to abiotic stress at some stage of development, which caused a reduction in yield. In contrast to plant resistance to biotic stresses, which is mostly dependent on monogenic traits, the response to abiotic stresses are multigenic, and thus more difficult to control and engineer (Vinocur and Altman 2005). Since proteins are directly involved in plant stress response, proteomics studies can significantly contribute to unravel the possible relationships between protein abundance and plant stress acclimation (Kosová et al. 2011). In addition to producing specific proteins, plants respond to various stresses in a similar manner by producing heat shock proteins (HSPs), indicating a similarity in the plant's adaptive mechanisms (Timperio et al. 2008). In this sense, the HSPs and other chaperones keep proteins and RNA in their correct conformation in order to mitigate extreme temperatures (Wang et al. 2004). Some of these HSPs are related to flour quality (Wardlaw et al. 2002).

Changes in individual gluten proteins (gliadins and glutenins) in response to temperature and drought have been observed (Altenbach 2012). The relationships between HSPs and glutenins show that the presence of a HSP 70 was not strongly correlated with loss of dough strength (Blumenthal et al. 1998), probably because glutenins were phosphorylated and glycosylated, indicating that these molecules were post-translationally modified (Lin et al. 2005). However, sequencing of the genes (upstream of the coding region) for high molecular weight glutenins failed to show the presence of heat-shock promoters (Blumenthal et al., 1998). On the other hand, various gliadin proteins act as heat-shock proteins, and indeed, multiple heat-shock elements are present in the published sequences of representative genes (Blumenthal et al. 1994). As a consequence of this relationship, a deterioration of flour quality has been suggested, but this has not been proved yet (Maestri et al. 2002).

Although there is no clear evidence that heat shock protein accumulation is related to wheat breadmaking quality (Maestri et al. 2002), developing cultivars adapted to the global climate change using a conventional breeding scheme (recurrent selection) performed under rain fed conditions of cultivation, subject frequently to temperature extremes and drought during grain filling, promote the ability to produce a viable seed, increased grain yield as well as improved flour quality. Taking into account these tendencies, any deterioration in quality must be caused by non-genetic factors. However, care should be taken to maintain current levels of dough strength so that it does not exceed the levels required for the breadmaking process.

In conclusion, concurrent breeding for higher grain yield and improved functional quality is feasible. Thanks to population genetic improvement mediated by a recurrent selection scheme conducted under rainfed conditions, genotypes tolerant to abiotic stresses were obtained. Moreover, industrial flour quality accompanied the genetic progress for 
grain yield. However, flour protein content would, at best, be maintained at current levels as yield increase.

\section{Acknowledgements}

The authors express their appreciation to Secyt-UNC for financial support. And they want to thank Gabriela Díaz Cortez who did the language quality check of this manuscript.

\section{References}

AACC 2000. Approved Methods of the American Association of Cereal Chemists. Am. Assoc. of Cereal Chem. St. Paul, MN. USA.

Altenbach, S.B. 2012. New insights into the effects of high temperature, drought and post-anthesis fertilizer on wheat grain development. J. Cereal Sci. 56:39-50.

Blumenthal, C., Wrigley, C.W., Batey, I.L., Barlow, E.W.R. 1994. The heat-shock response relevant to molecular and structural changes in wheat yield and quality. Austr. J. of Plant Physiol. 21:901-909.

Blumenthal, C., Stone, P.J., Gras, P.W., Bekes, F., Clarke, B., Barlow, E.W.R., Appels, R., Wrigley, C.W. 1998. Heat-shock protein 70 and dough-quality changes resulting from heat stress during grain filling in wheat. Cereal Chem. 75:43-50.

Brancourt-Hulmel, M., Doussinault, G., Lecomte, C., Bérard, P., Le Buanec, B., Trottet, M. 2003. Genetic improvement of agronomic traits of winter wheat cultivars released in France from 1946 to 1992. Crop Sci. 43:37-45.

Colombo, A., Pérez, G.T., Ribotta, P.D., León, A.E. 2008. A comparative study of physicochemical tests for quality prediction of Argentine wheat flours used as corrector flours and for cookie production. J. Cereal Sci. 45:775-780.

De Vita, P., Li Destri Nicosia, O., Nigro, F., Platani, C., Riefolo, C., Di Fonzo, N., Cattivelli, L. 2007. Breeding progress in morpho-physiological, agronomical and qualitative traits of durum wheat cultivars released in Italy during the 20th century. Eur. J. of Agron. 26:39-53.

Delzer, B.W., Busch, R.H., Hareland, G.A. 1995. Recurrent selection for grain protein in hard red spring wheat. Crop Sci. 35:730-735.

Di Rienzo, J.A., Casanoves, F., Balzarini, M.G., Gonzalez, L., Tablada, M., Robledo, C.W. InfoStat version 2013. Grupo InfoStat, FCA, Universidad Nacional de Córdoba, Argentina. URL http:/www.infostat.com.ar

Giunta, F., Motzo, R., Pruneddu, G. 2007. Trends since 1900 in the yield potential of Italian-bred durum wheat cultivars. Eur. J. Agron. 27:12-24.

Hristov, N., Mladenov, N., Djuric, V., Kondic-Spika, A., Marjanovic-Jeromela, A. 2010. Improvement of wheat quality in cultivars released in Serbia during the $20^{\text {th }}$ century. Cereal Res. Commun. 38:111-121.

Kosová, K., Vítámvás, P., Prášil, I.T., Renaut, J. 2011. Plant proteome changes under abiotic stress - contribution of proteomics studies to understanding plant stress response. J. of Proteomics 74:1301-1322.

Li, Y., Wu, Y., Hernandez-Espinosa, N., Peña, R.J. 2013. The influence of drought and heat stress on the expression of end-use quality parameters of common wheat. J. Cereal Sci. 57:73-78.

Lin, S.K., Chan, M.C., Tsai, Y.G., Lur, H.S. 2005. Proteomic analysis of the expression of proteins related to rice quality during caryopsis development and the effect of high temperature on expression. Proteomics 5:2140-2156.

Maich, R.H., Di Rienzo, J.A. 2014. Genotype $\times$ tillage interaction in a recurrent selection program in wheat. Cereal Res. Commun. 42:525-533.

Maestri, E., Klueva, N., Perrotta, C., Gulli, M., Nguyen, H.T., Marmiroli, N. 2002. Molecular genetics of heat tolerance and heat shock proteins in cereals. Plant Mol. Biol. 48:667-681.

Oelofse, R.M., Labuschagne, M.T., van Deventer, C.S. 2010. Influencing factors of sodium dodecyl sulfate sedimentation in bread wheat. J. Cereal Sci. 52:96-99. 
Oury, F.X., Godin, C. 2007. Yield and grain protein concentration in bread wheat: how to use the negative relationship between the two characters to identify favourable genotypes? Euphytica 157:45-57.

Peighambardoust, S.H., Ghamari, M., Naghavi, S. 2011. Application of gel-protein analysis compared to conventional quality tests in characterisation of Iranian wheat cultivars. Cereal Res. Commun. 39:394-404.

Tayyar, S. 2010.Variation in grain yield and quality of Romanian bread wheat varieties compared to local varieties in northwestern Turkey. Romanian Biotechnol. Letters 15:5189-5196.

Timperio, A.M., Egidi, M.G., Zolla, L. 2008. Proteomics applied on plant abiotic stresses: Role of heat shock proteins (HSP). J. of Proteomics 71:391-411.

Vinocur, B., Altman, A. 2005. Recent advances in engineering plant tolerance to abiotic stress: achievements and limitations. Current Opinion in Biotech. 16:123-132.

Wang, M.L., Zhao, Y., Chen, F., Yin, X.C. 2004. Inheritance and potentials of a mutated dwarfing gene ndf1 in Brassica napus. Plant Breeding 123:449-453.

Wardlaw, I.F., Blumenthal, C., Larroque, O., Wrigley, C.W. 2002. Contrasting effects of chronic heat stress and heat shock on kernel weight and flour quality in wheat. Functional Plant Biol. 29:25-34.

Zhou, Y., He, Z.H., Sui, X.X., Xia, X.C., Zhang, X.K., Zhang, G.S. 2007. Genetic improvement of grain yield and associated traits in the northern China winter wheat region from 1960 to 2000. Crop Sci. 47:245-253. 